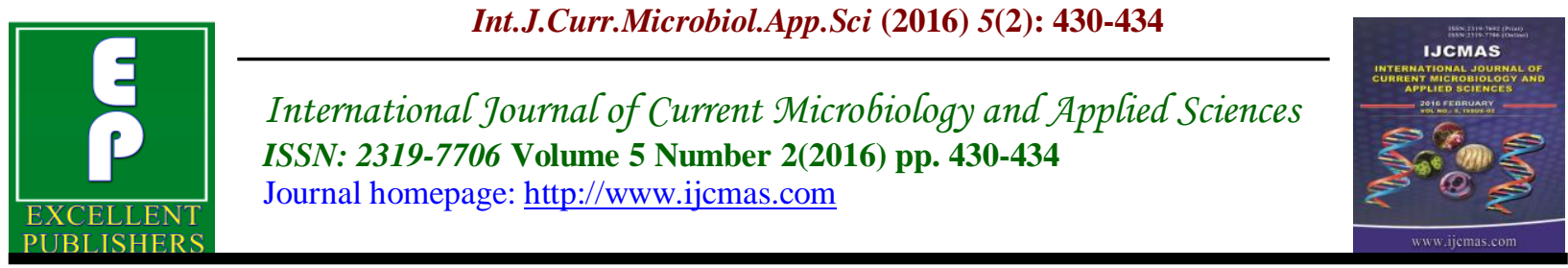

Original Research Article

doi: http://dx.doi.org/10.20546/ijcmas.2016.502.048

\title{
Emergence of Highly Resistant Klebsiella sp. in Tracheal Aspirates of Ventilated Patients in Critical Care Setup at Tertiary care Hospital in Western Rajasthan, India
}

\author{
R.S. Parihar ${ }^{1}$, Priyanka Soni ${ }^{1}$, P.K. Khatri ${ }^{1}$, Laxman Kumar Soni ${ }^{2}$ and Dalpat Singh ${ }^{3}$ \\ ${ }^{1}$ Department of Microbiology, Dr.S.N. Medical College, Jodhpur, India \\ ${ }^{2}$ Department of pulmonary Medicine, Dr.S.N. Medical College, Jodhpur, India \\ ${ }^{3}$ Department of Radio Diagnosis, Dr. S.N. Medical College, Jodhpur, India \\ *Corresponding author
}

\begin{abstract}
A B S T R A C T
Keywords

Endotracheal

aspirate,

Klebsiella,

Ventilated

Patients

ICU.

Article Info

Accepted:

23 January 2016

Available Online:

10, February 2016

Patients who are mechanically ventilated are at high risk of acquiring respiratory infections due to complex interplay between the endotracheal tube, host immunity and virulence of invading bacteria. To initiate empiric antimicrobial therapy knowledge of local antimicrobial resistance patterns are essential. Objective of study were to study the causative organisms and determine the antibiotic susceptibility pattern of tracheal isolates. Endotracheal aspirates from 240 patients admitted to the ICU were cultured, identified and antimicrobial susceptibility testing was performed by standard methods. Culture showed growth in 221(92\%) patients. Gram negative enteric aerobic bacteria were isolated from most of the patients. The most common being commonly isolated organism was Klebsiella species in 78(32.5\%), followed by Pseudomonas in 37 (15.4\%) and Acinectobector 35(14.6\%). Most of Klebsiella sp. were resistant to Cephalosporin (cefexime, cefuroxime, and ceftazidime). The antibiotics showed maximum sensitivity to Klebsiella sp. were imipenam and levofloxacin, followed by ciprofloxacin, aminoglycosides. (Figure 2). Gram negative organisms mostly susceptible to Carbapenem and fluoroquinolones group of antibiotics which were the predominant isolates in our critical care setup. A local antibiogram for each hospital, based on bacteriological patterns and susceptibilities is essential to initiate empiric therapy, to prevent poor outcomes and help in framing the appropriate institutional antibiotic policy.
\end{abstract}

\section{Introduction}

Patients with mechanical ventilation have an increased risk for respiratory tract infection because the tube which has been inserted into the trachea reduces the clearance of bacteria and increases the leakage of secretion around the cuff of the tube and disable the cilliary tract by damaging to it (1). Because of decreased salivary secretion, colonization of oropharynx with Gram negative bacteria is also probable in Ventilated patients (2-3).

In the literatures, the incidence of respiratory tract infection in relation to intubation and/ or mechanical ventilation has been reported to vary between $4 \%$ and 
$28 \%$ and this rate has been thought to be 21 times higher than in patients without endotracheal tube (4-8).

The international study of infection in ICU which was conducted in 2007, and involved with 1265 ICUs from 75 countries, demonstrated that patients who had longer ICU stays had higher rates of infection, especially infections due to resistant Staphylococci, Acinetobacter, Pseudomonas species, and Candida species. Moreover, the ICU mortality of infected patients was more than twice that of non-infected patients. [9] Most ICU patients that acquired infections are associated with the use of invasive devices such as catheters and mechanical ventilators [10].

Prevention of the emergence and dissemination of resistant microorganisms will reduce adverse events and their attendant costs. Appropriate antimicrobial stewardship that includes optimal selection, dose, and duration of treatment, as well as control of antimicrobial use, will prevent or slow the emergence of resistance among microorganisms [11]. Therefore, the present study was designed to know the bacterial profile and determine the antimicrobial resistance pattern among patients admitted to the ICU of our institute.

\section{Materials and Methods}

This was a cross sectional study during a period of 6 months from June to Dec. 2015. Total 240 patient admitted to Trauma ICU, Medical ICU and Surgical ICU, who were on mechanical ventilation, were included in this study. The following data were collected from the patients enrolled in the study: name, age, gender etc. ETA (endotracheal aspirate) was collected by ICU doctor, using all aseptic measures using suction catheter.
All the organisms were subjected to antimicrobial susceptibility testing including detection of various resistance mechanisms like ESBL and Cabapenemase resistance by manual methods as per recent CLSI guidelines. Antibiotic discs used for gram negative organisms were Imipenem, Ciprofloxacin, Ofloxacin, Levofloxacin, Cefuroxime, Ceftriaxone, Cefexime, ceftazidime, Amikacin, Gentamycin, tobramycin. For gram positive bacteria antibiotic disk of Linezolid, Vancomycin, Imipenem, Cefuroxime, Cefexime, ceftazidime, Ciprofloxacin, Ofloxacin, levofloxacin, amikacin were used. (12)

\section{Inclusion Criteria}

Adult patients aged above 18 years, who were mechanically ventilated for various reasons.

\section{Exclusion Criteria}

HIV positive patients, Post-op ventilated patients and Sputum smear acid fast bacilli (AFB) positive patients, patients not willing to consent were excluded in our study.

\section{Results and Discussion}

A total of 240 patients were enrolled in our study including $167(69.5 \%)$ were male and $73(30.5 \%)$ were female. Their average age was between 40-60 years. Among 240 patients, normal commensal of respiratory tract in $19(7.7 \%)$, Candida sp. in $8(3.3 \%)$, GPB in $7(3 \%)$ as contaminant, Gram positive cocci in $30(12.5 \%)$. The organism obtained were Klebsiella sp. in 78(32.5\%), Pseudomonas sp in $37(15.4 \%)$, Acinetobacter sp in 35(14.6\%), Staph aureus in 30(12.5\%). 
Table.1 Frequency of Organism Isolated from ICU

\begin{tabular}{|c|l|c|}
\hline S. No. & \multicolumn{1}{|c|}{ Organism } & Number(Percentage) \\
\hline 1. & Klebesiella sp. & $78(32.5 \%)$ \\
\hline 2. & Pseudomonas $s p$. & $37(15.4 \%)$ \\
\hline 3. & Acinetobactor & $35(14.6 \%)$ \\
\hline 4. & Esch. Coli & $4(1.7 \%)$ \\
\hline 5. & Proteus sp. & $6(2.5 \%)$ \\
\hline 6. & Citrobactor $s p$. & $16(6.6 \%)$ \\
\hline 7. & Staph. aureus & $30(12.5 \%)$ \\
\hline 9. & Candida sp. & $8(3.3 \%)$ \\
\hline 11. & GPB (Contaminant) & $7(3.0 \%)$ \\
\hline 12. & Normal Throat Commensal & $19(8.0 \%)$ \\
\hline 11. & Total (240) \\
\hline
\end{tabular}

Figure.1 Patients Infected by Klebsiella sp and its Antibiotic Sensitivity Pattern

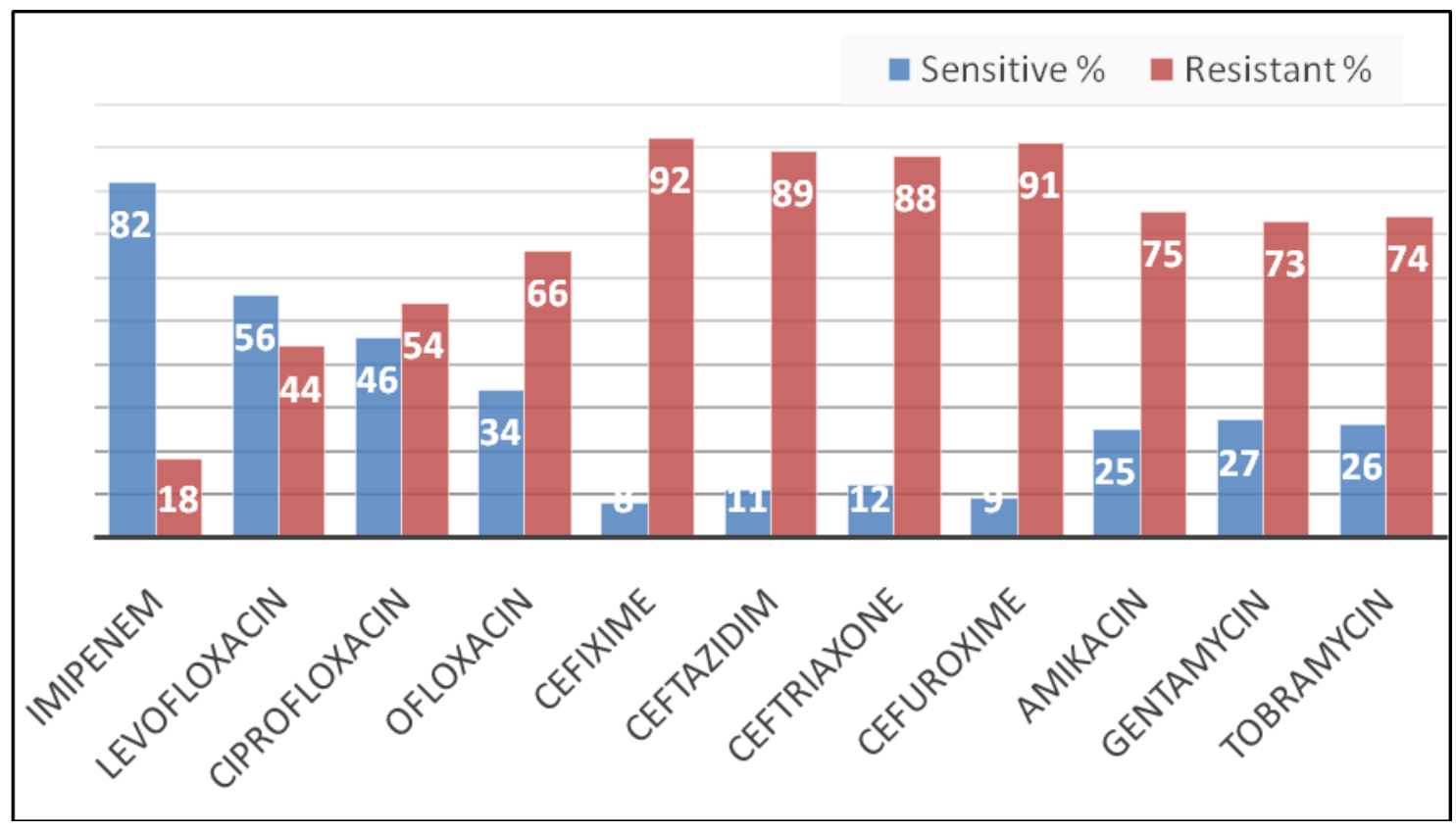

Klebsiella sp, were the most commonly isolated isolate present in 78(32.5\%) patients among both male and femlae. It was almost resistant to cephalosporin. The antibiotics showed higher sensitivity to Klebsiella sp. were imipenam and levofloxacin, followed by ciprofloxacin.

Infections are among the most important and the leading cause of mortality and morbidity in ICU. Endo-tracheal tubes are susceptible to infection and therefore it is important to be aware of the relevant factors and responsible organisms to take promptaction. The findings of this study would be helpful in selection of appropriate antibiotics.

In our study, GNB were most common cause of respiratory infection in ventilated patients, in which Klebsiella sp. is most commonly found. Klebsiella sp. show sensitivity to imipenam, levofloxacin, 
ciprofloxacin and resistant to cephalosporin. This finding suggests that imipenem should be used judiciously in ventilated patients to prevent any further increase in resistance to carbapenem antibiotics.

Similar result found by Anusha, et al, 2014 was found isolates in $34(75.5 \%)$ patients. Gram negative enteric aerobic bacteria were isolated from most of the patients. The most common being Klebsiella species in 13 (38.23\%), followed by Pseudomonas in 8 (23.52\%), Aerobic gram positive cocci i.e., Staphylococcus aureus isolated in 2(5.88\%) patients. Most of these organisms were susceptible to aminoglycoside and carbapenem antibiotics (13).

In contrast, Rello et al.,(1994) in their study have demonstrated that $P$. aeruginosa is the most common causative organism for infection of ET and this could be the result of large number of patients with chronic obstructive pulmonary disease (COPD) and long-time of intubation and even a previous history of antibiotic therapy (14). It should be noted that although there are minor variations in relative frequency of obtained organisms, different studies have reported varying sources of isolations as in our study we did report colonization of organisms into the ET tube while other studies may have considered ET-related infections in their study analysis.

Antibiotic disc sensitivity test results may vary with hospital setting, while infection rate in a hospital may depend on the hospital environment, antibiotic use and other infection control practices. All these would limit the applicability of the findings of this study to other hospital settings.

In conclusion, GNB mostly susceptible to Carbapenem and fluoroquinolones group of antibiotics which were the mostly isolates in our ICU patients. There is an alarmingly high rate of resistance to cephalosporin's, beta lactam-lactamase inhibitors, and aminoglycoside, although imipenem is still sensitive against most pathogens but resistance is rising. To combat the high antimicrobial resistance, every centre should have a strict hospital infection control policy which includes measures like judicious use of antimicrobial agents, use of rational antibiotic therapy, education programs and hand hygiene.

\section{References}

1. Craven DE, Kunches LM, Kilinsky V, Lichtenberg DA,Make BJ, McCabe WR. Risk factors for pneumonia and fatality in patients receiving continuous mechanical ventilation. Am Rev Respir Dis 1986; 133: 792-796.

2. Adair CG, Gorman SP, Feron BM, Byers LM, Jones DS,Goldsmith CE, et al. Implications of endotracheal tube biofilm for ventilator-associated pneumonia. Intensive Care Med 1999; 25: 1072-1076.

3. Dennesen P, van der Ven A, Vlasveld M, Lokker L,Ramsay G, Kessels A, et al. Inadequate salivary flowand poor oral mucosal status in intubated intensive careunit patients. Crit Care Med 2003; 31: 781-786.

4. Diaz E, Planas K, Rello J. [Infection associated withthe use of assistedventilation devices]. Enferm Infecc Microbiol Clin 2008; 26: 465-470.

5. Chastre J, Fagon JY. Ventilatorassociated pneumonia. Am J Respir Crit Care Med 2002; 165: 867-903.

6. Fortaleza CM, Abati PA, Batista MR, Dias A. Riskfactors for hospital-acquired pneumonia in non ventilated adults. Braz J Infect Dis 2009; 13: 284-288.

7. Chevret S, Hemmer M, Carlet J, Langer 
M. Incidence and risk factors of pneumonia acquired in intensive care units. Results from a multicenter prospective study on 996 patients. European Cooperative Group on Nosocomial Pneumonia. Intensive Care Med 1993; 19:256-264.

8. HHaley RW, Hooton TM, Culver DH, Stanley RC, EmoriTG, Hardison CD, et al. Nosocomial infections in U.S.hospitals, 1975-1976: estimated frequency by selected characteristics of patients. Am J Med 1981; 70: 947-959.

9. Vincent JL, Rello J, Marshall J, Silva E, Anzueto A, Martin CD, et al. International study of the prevalence and outcomes of infection in intensive care units. JAMA. 2009;302(21):2323-2329

10. Shulman L, Ost D. Managing infection in the critical care unit: How can infection control make the ICU safe. Crit Care Clin. 2005;21:111-128.

11. Shlaes DM, Gerding DN, John JF (Jr), Craig WA, Bornstein DL, Duncan RA, Eckman MR, Farrer WE, Greene WH,
Lorian V et al. Society for Healthcare Epidemiology of America and Infectious Diseases Society of America Joint Committee on the Prevention of Antimicrobial Resistance: guidelines for the prevention of antimicrobial resistance in hospitals Clin Infect Dis 1997; 25: 584-599.

12. Clinical and Laboratory Standards Institute (CLSI) 2011; Performance Standards for Antimicrobial Susceptibility Testing; Twenty first Informational Supplement. M100-S21; 31(1).

13. Anusha $\mathrm{N}$ et al $\mathbf{J}$ of Evidence Based Med \& Hlthcare, pISSN- 2349-2562, eISSN2349-2570/ Vol. 1/ Issue 9 / Oct. 31, 2014. Page 1177.

14. Rello J, Ausina V, Ricart M, Puzo C, Quintana E, NetA, et al. Risk factors for infection by Pseudomonas aeruginosa in patients with ventilator-associated pneumonia. Intensive Care Med 1994; 20: 193-198.

\section{How to cite this article:}

Parihar, R.S., Priyanka Soni, P.K. Khatri, Laxman Kumar Soni and Dalpat Singh. 2016. Emergence of Highly Resistant Klebsiella sp. in Tracheal Aspirates of Ventilated Patients in Critical Care Setup at Tertiary care Hospital in Western Rajasthan, India. Int.J.Curr.Microbiol.App.Sci.5(2): 430-434. doi: http://dx.doi.org/10.20546/ijcmas.2016.502.048 